\title{
W KWESTII POCZĄTKÓW WCZESNEGO ŚREDNIOWIECZA W REJONIE NIECKI JEZIOR BNIŃSKICH
}

\author{
ON THE BEGINNINGS OF THE EARLY MIDDLE AGES IN THE AREA \\ OF THE BNIN LAKES BASIN
}

\begin{abstract}
The development of archaeological research justifies the need for re-appraising previous conclusions. In the case of the Bnin Lakes Basin (Wielkopolska), the research pertains to the settlement at the early stage of the early Middle Ages. Human settlement developed dynamically at phase B of the early Middle Ages. To date, settlement from phase A has not been discovered in the Basin. The same holds true for the basin of the central river Warta.
\end{abstract}

Keywords: settlement, the early medieval culture, Wielkopolska.

Wyniki prowadzonych $\mathrm{w}$ ostatnich latach badań archeologicznych $\mathrm{w}$ rejonie Niecki Jezior Bnińskich, w porównaniu do stanu badań do połowy lat 80 . XX wie$\mathrm{ku}$, czego wyrazem były informacje zawarte w czterech tomach o wczesnym średniowieczu, wydane pod redakcją Jana Żaka i Jerzego Fogla (1975; 1976; 1979; 1985), dostarczyły nowych danych uzasadniających potrzebę niekiedy uzupełnienia argumentacji na rzecz wcześniej już sformułowanych ustaleń. Owe badania wpisują się w obraz dynamicznie realizowanego ostatnio procesu pozyskiwania nowych źródeł archeologicznych o początkach wczesnego średniowiecza w środkowej Wielkopolsce, zwłaszcza w dorzeczu środkowej Warty, powodujące pilną potrzebę przewartościowania tutaj wielu dotychczas postawionych sugestii (por. Krzyszowski 2010, s. 183-191; Pawlak E. i P. 2018, s. 43-79).

W badaniach nad Jeziorami Bnińskimi, których efektem są wspomniane cztery tomy opracowań, uczestniczył profesor Wojciech Dzieduszycki, członek tzw. „,bnińskiej szkoły archeologicznej” (por. Fogel 2001, s. 59-63). On to, razem z Żoną, był autorem pierwszej rozprawy o tym rejonie poświeconej kulturze wczesnego

* ORCID 0000-0001-7213-9915, Instytut Archeologii i Etnologii, Uniwersytet Gdańsk, ul. Bielańska 5, 80-851 Gdańsk, e-mail: henryk.machajewski@ug.edu.pl. 
średniowiecza (Dzieduszyccy B. i W. 1985, s. 141-198). Podstawą źródłową dla tego opracowania, zwłaszcza początkowych jej etapów, były informacje pochodzące z przypadkowych jedynie odkryć i prowadzonej systemowej penetracji powierzchniowej, wykonywanej w ramach akcji „Archeologicznego Zdjęcia Polski”. Ocena chronologii wykorzystanych źródeł ceramicznych, ustalona na podstawie cech techniki jej wykonania, zwłaszcza dla początkowych faz wczesnego średniowiecza, budzić mogła niekiedy wątpliwości (Dzieduszyccy B. i W. 1985, s. 146-150). Dopiero późniejsze etapy rozwoju tej kultury, zasadniczo od fazy D, ocenione na podstawie wyników stacjonarnych badań wykopaliskowych i pozyskanych bogatych zestawów źródeł, nakreślono w sposób kompleksowy.

Początek zatem kultury wczesnego średniowiecza w rejonie Rynny Jezior Bnińskich, w ujęciu B. i W. Dzieduszyckich (1985, s. 148-149), nastąpił już w fazie B. W tym czasie funkcjonowało osadnictwo w okolicy Bnina, Prusinowa i Zaniemyśla, a więc po jej stronie wschodniej (ryc. 1). Natomiast w fazie D nastąpił dynamiczny jej rozwój. Wtedy, obok osadnictwa otwartego, powstały tam także założenia osadnictwa obronnego.

W ostatnich latach uzyskano nowe informacje archeologiczne o początkach osadnictwa wczesnośredniowiecznego w rejonie Niecki Jezior Bnińskich. Pochodzą one z badań wykopaliskowych prowadzonych na czterech stanowiskach w trakcie prac poprzedzających różnego rodzaju inwestycje budowlane. I tak, prace archeologiczne w Bninie, stan. 20 prowadziła Ewa Pawlak z Pracowni Archeologiczno-Konserwatorskiej Aliny Jaszewskiej (Zielona Góra), natomiast w Kórniku, stan. 31 Paweł Pawlak z Pracowni Archeologiczno-Konserwatorskiej Henryka Klundera (Poznań), natomiast w Jeziorach Wielkich, stan. 7 i w Skrzynkach, stan. 7 Henryk Machajewski z Firmy „Archeolog” (Poznań) (tabela 1).

Tabela 1. Zestawienie stanowisk z początków wczesnego średniowiecza z rejonu Rynny Jezior Bnińskich rozpoznanych w latach 2006-2018

\begin{tabular}{|c|c|c|c|c|}
\hline Lp. & Miejscowość & Rodzaj & Chronologia & Literatura \\
\hline 1. & Bnin, st. 20 & Osada & VII - pocz. VIII w. & E. Pawlak 2014 \\
\hline 2. & Kórnik, st. 31 & Osada & VII - VIII w. & Materiały w opracowaniu \\
\hline 3. & Jeziory Wielkie, st. 7 & Osada & VII - VIII w. & H. Machajewski 2014 \\
\hline 4. & Skrzynki, st. 7 & Osada & VII - pocz. VIII w. & H. Machajewski 2021 \\
\hline
\end{tabular}

Przedmiotem tych uwag są wyniki badań na stanowisku 7 w Skrzynkach, gmina Kórnik, gdzie odkryto pozostałości po osadzie (AZP: 55 - 29/nr 39). Jest ona zlokalizowana na północno-wschodniej rozległej terasie nadzalewowej Jeziora Skrzyneckiego, od wschodu otoczona niewielką równiną akumulacji biogenicznej 


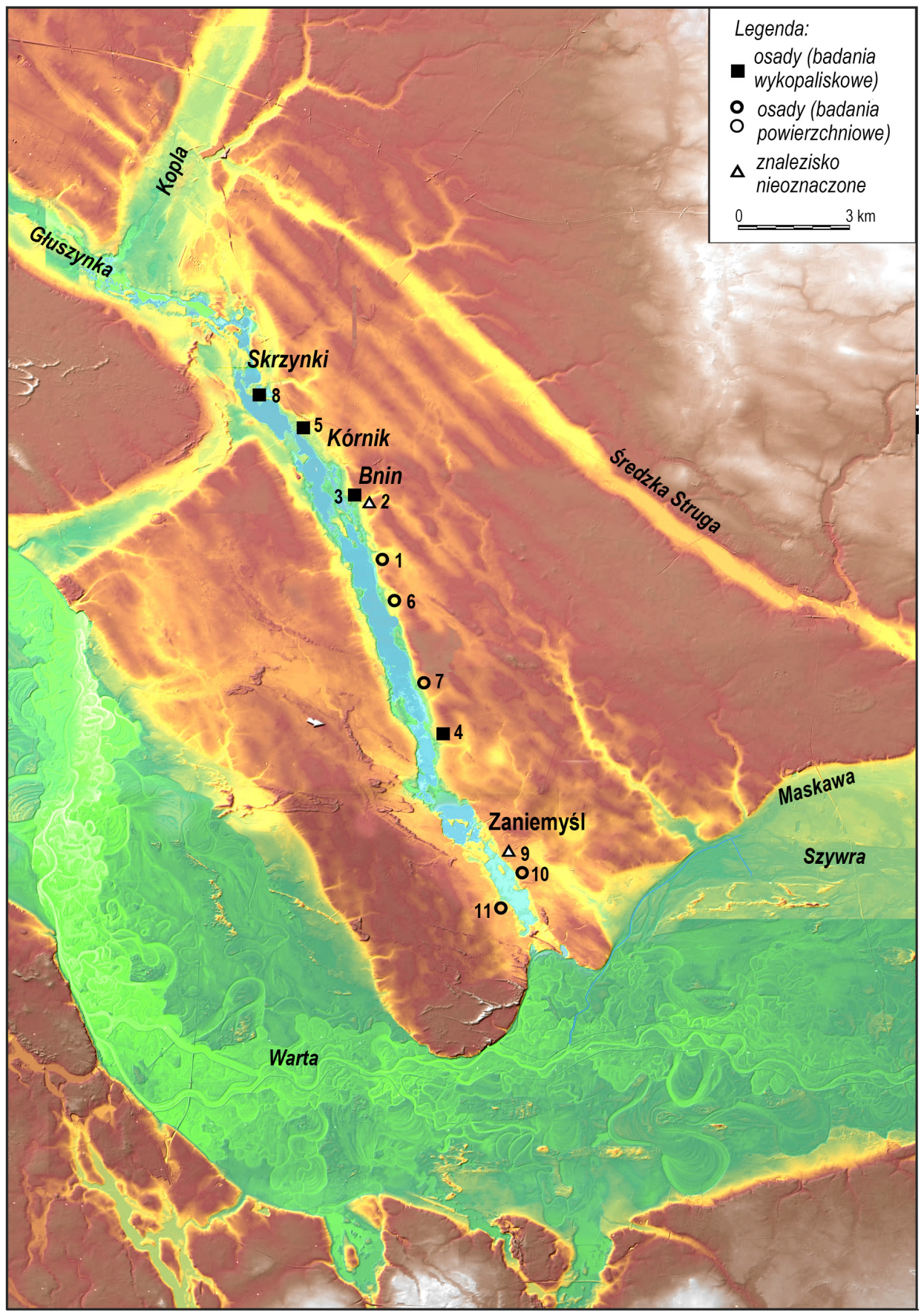

Ryc. 1. Osadnictwo w Niecce Jezior Bnińskich w fazie $B, B / C$ wczesnego średniowiecza. Oprac. H. Machajewski, rys. Ewa Pawlak 

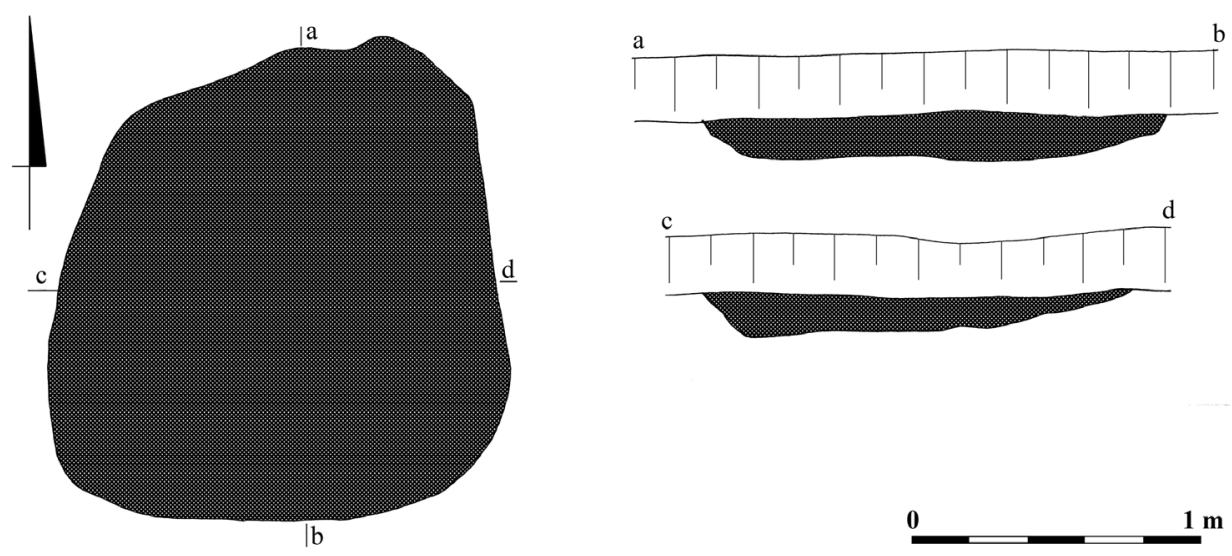

Ryc. 2. Skrzynki, gmina Kórnik, stanowisko 7; obiekt 1 (jama gospodarcza). Rzut poziomy i przekrój. Rys. Ewa Pawlak

(por. B. Nowaczyk 1985, s. 11-13). Na obszarze około $240 \mathrm{~m}^{2}$, w centralnej części wykopu budowlanego stwierdzono tylko jamę gospodarczą (obiekt 1), zlokalizowaną na linii N-S, kształtu nieregularnego prostokąta o wymiarach 2,05 $\times 1,60 \mathrm{~m}$, w przekroju nieckowatym, miąższości $0,26 \mathrm{~m}$. Wypełnisko jamy tworzyła spalenizna przemieszana z ciemnobrunatnym piaskiem (ryc. 2). Inwentarz to 47 fragmentów ceramiki naczyniowej wykonanych techniką częściowego obtaczania, z domieszką tłucznia granitowego, o przełamie dwubarwnym, powierzchniach obmazywanych, fakturze wygładzanej, barwie zewnętrznej brunatnej, wewnętrznej brunatnej lub szarej. $Z$ grupy 47 fragmentów naczyń wydzielono przynajmniej sześć ich form. Pierwsze dwa $\mathrm{z}$ nich to garnki smukłe, z brzegiem wygiętym na zewnątrz, z załomem brzuśca umieszczonym w 3/4 wysokości naczynia (ryc. 3:1; ryc. 4:1). Niewykluczone, że podobne formy garnków reprezentują także trzy kolejne ich fragmenty (ryc. 3:2-4). Natomiast dwa następne okazy to garnki dwustożkowate o wyraźnie zaznaczonym załomie brzuśca (ryc. 4:2-3).

Naczynia z jamy gospodarczej w Skrzynkach nawiązują do okazów spotykanych na pobliskich osadach odkrytych ostatnio w dorzeczu środkowej Warty. Garnki smukłe nawiązują do okazów z pobliskiego Bnina, gmina Kórnik, stan. 20, gdzie odpowiadają naczyniom odmiany G (Pawlak 2014, s. 271), datowanych na schyłek VII i początek VIII wieku, a także z nieco dalej położonej osady w Markowicach, gmina Kleszczewo, stan. 26, nawiązujących do naczyń typu D (Pawlak E. i P. 2008b, s. 57), natomiast w Kijewie, gmina Środa Wlkp., stan. 4, przypominają naczynia grupy II (Pawlak E. i P. 2008a, s. 232-233). Wszystkie wymienione naczynia są datowane na schyłek VII i początek VIII wieku. 

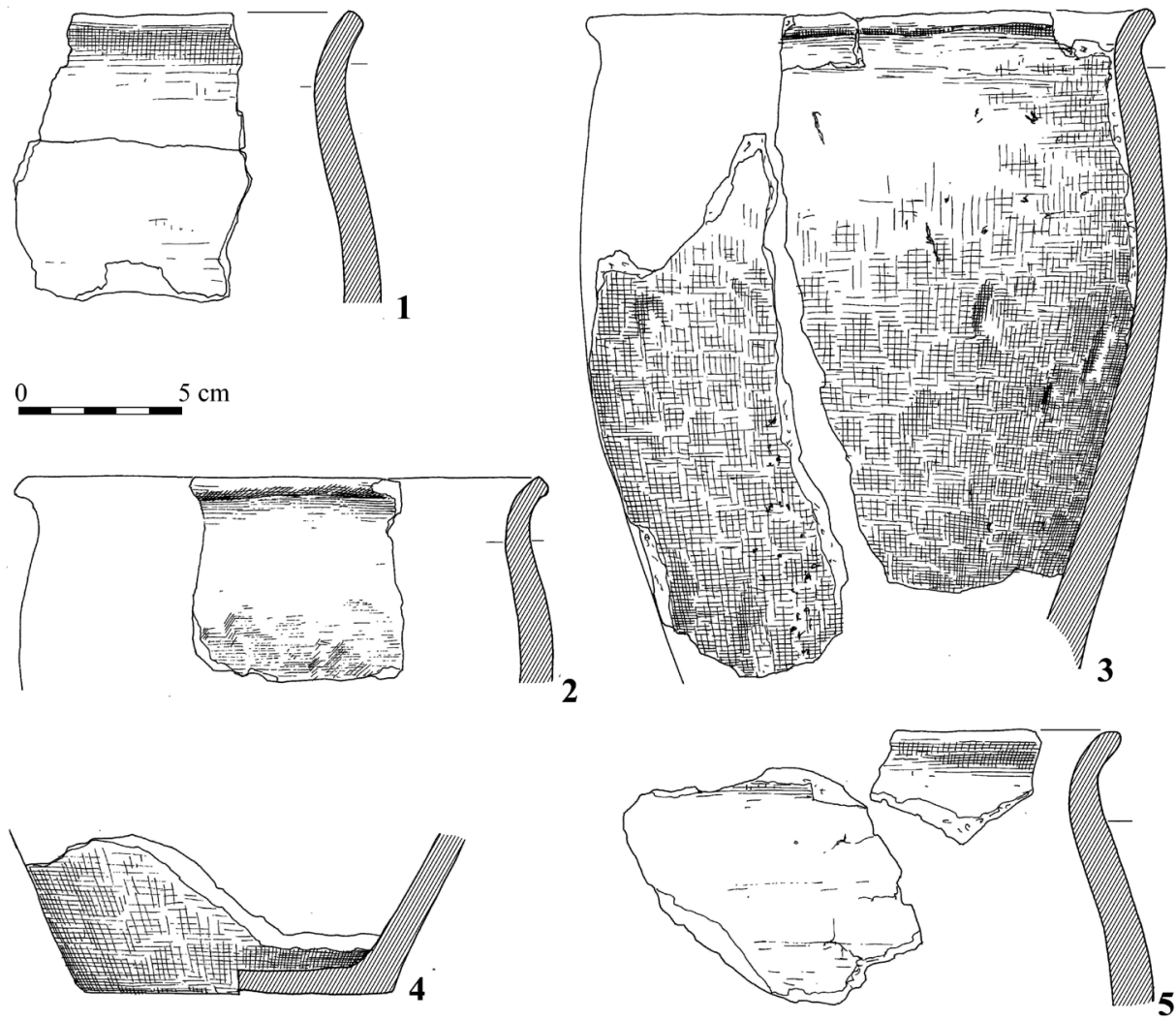

Ryc. 3. Skrzynki, gmina Kórnik, stanowisko 7; obiekt 1 (jama gospodarcza) - ceramika naczyniowa. Rys. Ewa Pawlak

Także garnki dwustożkowate znajdują nawiązania wśród naczyń pochodzących z tych samych osad, a mianowicie w Bninie odpowiadają odmianie F (Pawlak E. 2014, s. 268-271), w Markowicach typowi G (Pawlak E. i P. 2008b, s. 58), a w Kijewie grupie III (Pawlak E. i P. 2008a, s. 233). Wszystkie wyznaczają początkowe etapy rozwoju tych osad przypadających na schyłek VII i początek VIII wieku.

Tak więc jamę gospodarczą z osady w Skrzynkach użytkowano zapewne u schyłku VII lub na początku VIII wieku.

Pozostałości po osadzie w Skrzynkach, wraz z innymi ostatnio odkrytymi osadami (Bnin, stan. 20; Kórnik, stan. 31; Jeziory Wielkie, stan. 7), a także dawniej już znanymi punktami osadniczymi wydzielonymi przez B. i W. Dzieduszyckich (1985, s. 189, ryc. 31), wyznaczają zapewne najwcześniejszy, relatywnie szeroko udokumentowany, horyzont osadnictwa wczesnośredniowiecznego w Niecce Jezior Bnińskich datowany na fazę B. Wszystkie dotychczas odkryte pozostałości z tej fazy sytuują się na wschodniej stronie tej Niecki (ryc. 1). Preferowanie w tym 

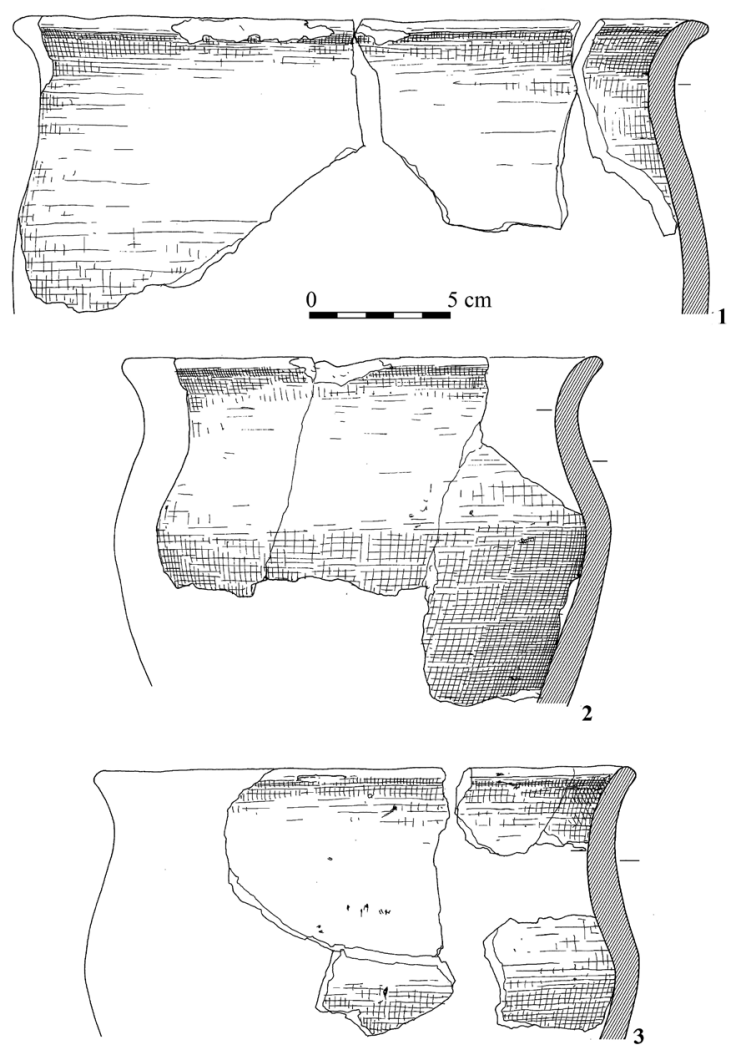

Ryc. 4. Skrzynki, gmina Kórnik, stanowisko 7; obiekt 1 (jama gospodarcza) - ceramika naczyniowa (ciąg dalszy). Rys. Ewa Pawlak

czasie siedlisk położonych w tej części Niecki nie jest zjawiskiem wyjątkowym. Znakomita część odkrytych w tej Niecce wszystkich pozostałości po dawnym osadnictwie pradziejowym była lokowana także po jej wschodniej stronie. Zauważa się jednocześnie, że obszar na zachód od Niecki, sięgający dorzecza środkowej Warty, nie znajdował się w sferze szczególnego zainteresowania dawnych społeczności. Przeciwieństwem jest dopiero szeroko ujmowana pradolina środkowej Warty w rejonie Młodzikowa, a dalej Śremu, Niesłabina, Mechlina i Sowinek.

Natomiast tereny na wschód od Niecki Jezior Bnińskich były znacznie częściej wykorzystywane pod osadnictwo, zwłaszcza pradolina Średzkiej Strugi, Moskawy i cieków doń uchodzących. Warto jednocześnie zauważyć, że na terenie między środkową Wartą a Średzką Strugą i Moskawą osadnictwo pochodzące ze schyłku starożytności (faza C1b - C2, D), poprzedzające osadnictwo z najwcześniejszych etapów wczesnego średniowiecza, skupione było w pradolinie Średzkiej Strugi 
i Moskawy, zwłaszcza przy jej ujściu do Warty, rzadziej w dorzeczu środkowej Warty, wyjątkowo natomiast w Niecce Jezior Bnińskich (por. Machajewski 1985, s. 119-129, mapa 12; Machajewski 1986, mapa 5; Machajewski 2018, s. 31-41)

W tak ogólnie tylko nakreślonej sieci osadniczej u schyłku starożytności osadnictwo w najwcześniejszych etapach wczesnego średniowiecza (faza A - B/C), zgodnie z ustaleniami Ewy i Pawła Pawlaków (2008 b, 136, ryc. 47), rozwijało się między Niecką Jezior Bnińskich a dolnym biegiem Średzkiej Strugi i Moskawy. Owa Niecka znalazła się zapewne w strefie szczególnego zainteresowania społeczności wczesnośredniowiecznej. Zastanawia brak lub słabo jeszcze udokumentowane w tej Niecce, szerzej w dorzeczu środkowej Warty, osadnictwa związanego z fazą A wczesnego średniowiecza (por. Hilczerówna 1967, s. 140-168, mapa 2; Parczewski 1988, s. 21, ryc. 2; Brzostowicz 2002, s. 223-230). Problem ten sprowadza się jednak do pytania, czy wyznaczanie w ogóle najwcześniejszego osadnictwa wczesnośredniowiecznego na podstawie naczyń ceramicznych ręcznie lepionych nawiązujące do grupy A jest uzasadnione (por. A. Krzyszowski 2010, s. 183-191). Czy proces ten mógł być bardziej jednak złożony i sprowadzał się do sytuacji, że najwcześniejsze osadnictwo tego okresu, przynajmniej w części dorzecza środkowej Warty, chociażby na gruncie źródeł archeologicznych, mogły wyznaczać zespoły $\mathrm{z}$ ceramiką śladowo już obtaczane przy krawędziach, pochodzące dopiero z fazy B, a więc z końca VII wieku?

\section{BIBLIOGRAFIA}

Brzostowicz M. Bruszczewski zespół osadniczy we wczesnym średniowieczu, Poznań.

Dzieduszyccy B. i W. Osadnictwo wczesnośredniowieczne $w$ rejonie Niecki Jezior Bnińskich, w: J. Żak,

J. Fogel (red.), Materiały do studiów nad osadnictwem bnińskim. Mikroregion bniński, Poznań, s. 141-198.

Fogel J. „Bnińska szkoła archeologiczna”, w: D. Minta-Tworzowska, Wł. Rączkowski (red.), Archeologia. Paradygmat. Pamięć, Poznań, s. 59-63.

Hilczerówna Z. Dorzecze górnej i środkowej Obry od VI do początków XI wieku, Wrocław-Warszawa- Kraków.

Krzyszowski A. Rytualne paleniska czy obiekty grobowe (?) z przełomu okresu późnorzymskiego i wczesnych faz wczesnego średniowiecza w Wilanowie (stan. 12), gmina Kamieniec, woj. wielkopolskie, „Slavia Antiqua” t. 51, s. 165-203.

Machajewski H. Z badań nad osadnictwem Niecki Jezior Bnińskich w młodszym okresie przedrzymskim $i$ okresie rzymskim, w: J. Żak, J. Fogel (red.), Materiały do studiów nad osadnictwem bnińskim. Mikroregion bniński, Poznań, s. 119-139.

- Stan badań nad młodszym okresem przedrzymskim i okresem rzymskim $w$ Wielkopolsce, K. Godłowski, R. Madyda-Legutko (red.), Stan i potrzeby badań nad młodszym okresem przedrzymskim i okresem wpływów rzymskich w Polsce, Kraków, s. 269-298.

- Ze studiów nad wczesnym okresem wędrówek ludów w Wielkopolsce, H. Machajewski (red.), Archeologia dawnego osadnictwa Wielkopolski, Poznań, s. 31-41.

Nowaczyk B. Rozwój geomorfologiczny rynny glacjalnej Jezior Kórnicko-Zaniemyskich (Bnińskich) w aspekcie osadniczym, w: J. Żak, J. Fogel (red.), Materiały do studiów nad osadnictwem bnińskim. Mikroregion bniński, Poznań, s. 7-20. 
Pawlak E. Wyniki badań archeologicznych przeprowadzonych w 2013 r. na wielokulturowej osadzie na stanowisku 20 w Bninie, gm. Kórnik, woj. wielkopolskie, Raport 9, s. 241-291.

Pawlak E. i P. 2008a, Osada wczesnośredniowieczna oraz relikty z okresu nowożytnego (Kijewo), w: E. Pawlak, P. Pawlak, J. Kabaciński, I. Sobkowiak-Tabaka, L. Czerniak, D. Prinke, P. Silska, H. Machajewski, A. Rewekant, A. Sikorski, Kijewo, stanowisko 4, pow. średzki. Materiaty do badań nad osadnictwem pradziejowym i wczesnośredniowiecznym, Fontes Archaeologici Posnanienses, vol. 44, s. 185-342.

- 2008b, Osiedla wczesnośredniowieczne w Markowicach pod Poznaniem wraz z pozostatościami osadnictwa pradziejowego, Poznań.

- Najdawniejsze siedziby Stowian w Wielkopolsce na podstawie wybranych źródet archeologicznych, H. Machajewski (red.), Archeologia dawnego osadnictwa Wielkopolski, Poznań, s. 43-79.

Parczewski M. 1988, Poczatki kultury wczesnostowiańskiej w Polsce. Krytyka i datowanie źródeł archeologicznych, Wrocław-Warszawa-Kraków-Gdański-Łódź.

Żak J., Fogel J. (red.), Materiały do studiów nad osadnictwem bnińskim. Grodzisko wklęste, Poznań.

- Materiaty do studiów nad osadnictwem bnińskim. Grodzisko stożkowate, Warszawa-Poznań.

- Materiaty do studiów nad osadnictwem bnińskim. Podgrodzie, Warszawa-Poznań.

- 1985, Materiaty do studiów nad osadnictwem bnińskim. Mikroregion bniński, Poznań. 